\title{
Developing the hertz art-science project to allow inaudible sounds of the Earth and cosmos to be experienced
}

\author{
Graeme J. Marlton ${ }^{1}$ and Juliet Robson ${ }^{2}$ \\ ${ }^{1}$ Department of Meteorology, University of Reading, Reading, RG6 6BB, UK \\ ${ }^{2}$ Wyfold Lane Studio, Wyfold Lane, Peppard Common, Henley-on-Thames, RG9 5LR, UK
}

Correspondence: Graeme J. Marlton (graeme.marlton@reading.ac.uk)

Received: 28 February 2020 - Discussion started: 16 March 2020

Revised: 1 September 2020 - Accepted: 18 September 2020 - Published: 25 November 2020

Abstract. The Earth and atmosphere are in constant motion. Volcanoes, glaciers, earthquakes, thunderstorms, and even the aurora borealis produce powerful low-frequency sounds known as infrasound. Infrasound is constantly passing through our atmosphere at frequencies of less than $20 \mathrm{~Hz}$, below the range of human hearing, which is effectively an inaudible symphony. Inspired by wanting to allow physical access to this natural phenomenon, a collaboration between the worlds of contemporary art and meteorology has been developed. This led to a project called hertz, named after the 19th century physicist Heinrich Hertz, whose surname provides the scientific unit $(\mathrm{Hz})$ for frequency. Hertz explores the manifestation of the hidden vibrations of our own planet and the secret harmonies of our stars. The manifestation of the hidden vibrations of our own planet was principally achieved using a subwoofer and furniture adapted to vibrate to the amplitude of infrasonic waves from pre-recorded sources and in real time. The project's motivations are to explore new methods for experiencing and re-engaging with parts of our planet through this phenomenon. Hertz has had a UK national tour in which 7000 people interacted with the piece, of which approximately $85 \%$ felt more reconnected to the environment after interacting with the installation. This paper describes the concepts, creative ideas, technology, and science behind the project. It addresses its development, including the steps to make it accessible for all, and examines its impact on those who created and interacted with the work.

\section{Introduction}

The Earth and atmosphere are in constant motion due to a range of natural processes such as seismic activity, volcanic eruptions, and glacial slippage. Atmospheric phenomena such as hurricanes, thunderstorms, and tornadoes also contribute. At first, these events can be both majestic and alarming. Increasingly, these are rarely experienced directly, as more of the Earth's population live in towns and cities, insulated from these expressions of nature. The acoustic signals of natural terrestrial and atmospheric changes are evermore obscured by the background anthropogenic noise of airports, trains, and motorways. Technology further isolates the modern human from the natural environment in which we evolved. Seeking to reinvigorate and inspire our relationship with the natural environment through the use of inaudible frequencies, one of us, the artist Juliet Robson, aimed to create an interactive artwork that would re-establish this diminishing link. Robson wanted to create a piece that was tangible in a very real sense and that allowed a way into the important, but sometimes inaccessible, research done by scientists. This would align with the view that "Artists are no longer concerned with creating artwork that reflects or interprets reality; rather, they want to be active agents in creating it ... That means that artists need to have an even deeper understanding of the mechanics behind science and technology" (Williams, 2017).

To undertake this, it was apparent that such a project would need to call on science, technology, engineering, and maths (STEM) expertise to create an as authentic as possible representation of natural hidden vibrations through an immersive experience. Robson approached two scientists and a 
mathematician to explore the possibilities of making the hidden frequencies of the stars and natural phenomena of our planet heard and felt. Art-science collaborations highlighting the unseen and intangible processes occurring around us that are demonstrated to the wider public have been undertaken before and continue to generate interest. Ezquerro et al. (2019) sonified sediment samples to make 14 distinct compositions based on the lithography and structure of each sample. Hooker (2011) designed an installation which detected high-energy particles from outside our solar system, which pass through humans without leaving a trace, and used it to trigger notes on an electric piano. Collaborating with scientists and researchers globally, Patterson (2007) created a phone line that could be called from anywhere in the world through which one could listen to a glacier melting. In addition to this, McMullen (2005) described how a group of artists worked with scientists at the European Organization for Nuclear Research (CERN) to create artworks which reflected theories in the realm of physics, such as the crumple effect.

One of the scientists Robson contacted was co-author Graeme Marlton, a meteorologist who was working on the Atmospheric Research Infrastructure in Europe 2 (ARISE 2) project (Blanc et al., 2018). The project encompassed the examination of a multitude of different novel measurement techniques to measure the dynamical properties of the atmosphere. One such technology utilised in ARISE2 was infrasound measurements. Infrasound contains sound frequencies which fall below the audible range of human hearing and are essentially sound waves below $20 \mathrm{~Hz}$. It is produced naturally or artificially by large explosions, such as that of a nuclear detonation or by mining activity, and trains and planes. Natural infrasound is produced by volcanoes, earthquakes, glaciers, ocean swell, thunderstorms, hurricanes, and even the aurora borealis (Wilson, 1969), as shown in Fig. 1. The importance of infrasound in the ARISE project was learning about the state of the atmosphere by examining how infrasonic waves passed through it from a known infrasound source, such as a volcano (Smets et al., 2019).

It was suggested by Marlton that infrasound could be used as a medium for Robson's new project, and Robson was interested in the possibility of experiencing its inaudible symphony. Infrasound has featured in art installations before. Granchow (2015) produced an installation called the "Longwave synthesis" which aimed to challenge how we perceive our environment and long-wave vibration. Grupfinger (2009) built an installation that allowed the audience to experiment with and experience a range of infrasound. Anish Kapoor (Aerotrope, 2012) produced an installation entitled "anxious" with an engineering company that played infrasound through the body at $18 \mathrm{~Hz}$ in a confined place to emulate the feeling the space was haunted. Barres (2017) discussed, in a review of Kapoor's works, how Kapoor was not successful as the installation caused anxiety in the visitors and museum staff.

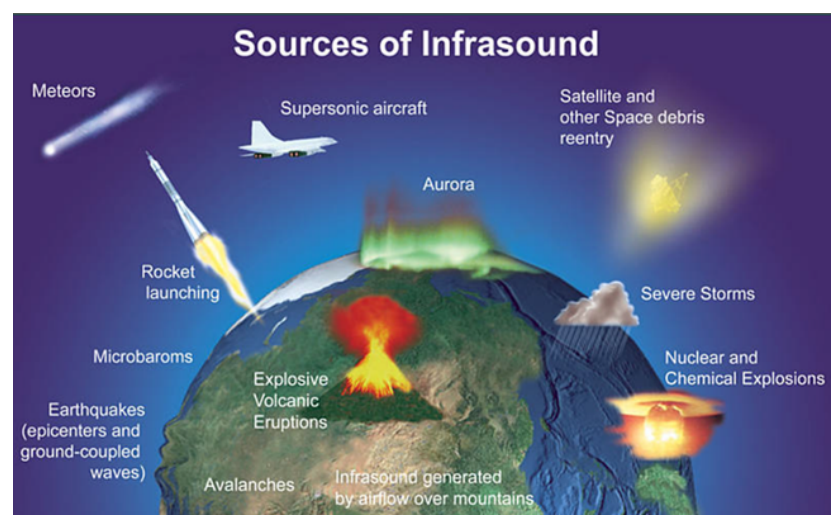

Figure 1. Sources of infrasound, both artificial and naturally occurring, from the ARISE website (http://arise-project.eu/, last access: 2017).

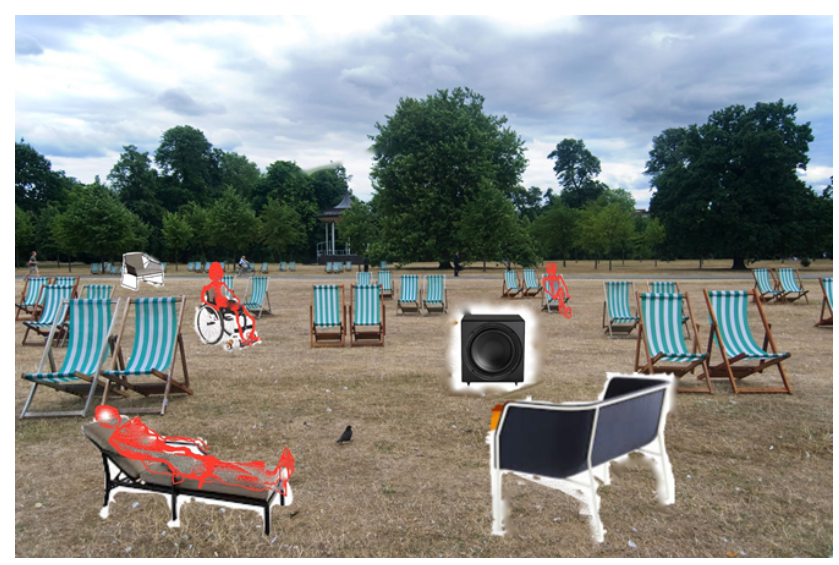

Figure 2. One of Robson's initial drawings of hertz in an urban park showing blue and white striped deck chairs, other furniture, and a wheelchair. Three people are sitting, namely one in a deck chair, one in a wheelchair, and one lying on a sun lounger. The figures are drawn in red. Placed among the furniture is a large subwoofer. The furniture would have transducers attached to them to vibrate them, and the subwoofer would play the sounds of a large ocean wave or a storm a long way off the coast.

To provide new access to natural infrasound, the raw infrasound data could be processed to provide a sound wave which could be played through commercially available transducers. Transducers are devices which shake when a lowfrequency sound is played through them. They are fitted in $4 \mathrm{D}$ cinemas and video gaming chairs to provide a vibrating sensation to the spectator when an explosion or aircraft passes over on the screen to make the experience more immersive. The aim here was to enable people to feel their bodies resonating with the inaudible symphony of the planet. Figure 2 shows the initial concept work drawn up for the project. This would become one of the two working strands for Robson's immersive new project. 
The other strand is not discussed at length here, but a brief description is given. It took astronomical measurements of the stars and, from their spectral signature, derived a sound wave. Sound waves move through a star's gaseous interior because of temperature changes, which cause the star to fluctuate in brightness. Satellites, such as the North American Space Agency (NASA)'s Kepler satellite and the Transiting Exoplanet Survey Satellite, can observe these vibrations. Data for hertz were obtained from NASA's Kepler project (Chaplin et al., 2011) and then sonified and played through Chladni plates built for the project. Chladni plates consist of a flat sheet of metal, usually circular or square, mounted on a central stalk on a sturdy base. When the plate oscillates during a mode of the vibration, the nodes and antinodes form complex but symmetrical patterns over its surface. The positions of these nodes and antinodes can be seen by sprinkling sand upon the plates. The sand will vibrate away from the antinodes and gather at the nodes (Stöckmann, 2007). As the frequencies of different stars were played through the plates, the sand sprinkled on the plate formed geometric patterns related to that star's frequency. Chladni plates have been used as a method of visualising sounds and music, as documented by Stanford (2013).

As the connection between the two strands was that of vibrations, oscillations, and resonance, which are associated with frequency, the project was named hertz, after the standard unit of frequency. Drawing on the fact that everything vibrates, from the smallest atom to the furthest star and that their frequencies surround us and yet leave no imprint, hertz enables people to feel their bodies resonating to the inaudible symphony of our own planet, experience the stars singing, and see their sound made visible. Hertz's ultimate goal would aim to reconnect us to our planet and place in the cosmos. Its ancillary aims would also be to educate about the science behind the project.

In this paper, we predominantly focus on the infrasound strand of the hertz project. In Sect. 2, we will describe the science behind how the installation works and the initial feedback received on the prototype. In Sect. 3, we describe how the feedback modelled the version prepared for the hertz tour around the UK. Section 4 discusses the accessibility considerations for the project and tour. Section 5 discusses the hertz set-up at each of the three UK tour locations. In Sect. 6 we review the feedback from the public from the tour. In Sect. 7 , we discuss the collaboration between the artist and the scientist. The project findings are summarised in the conclusions in Sect. 8.

\section{Hertz - from concept to prototype}

To create an immersive experience where modified infrasound is played through a transducer, infrasound recordings which had captured the acoustics of the natural world were needed. In this section, we describe how infrasound is mea- sured and how the infrasonic recordings used in the hertz project were acquired. We will then describe the prototype set-up and how the infrasound recordings were processed to create an immersive experience.

\subsection{Infrasound recordings}

Infrasound cannot be detected using normal audio recording equipment. Instead, a microbarometer, a very sensitive pressure sensor, can be used to detect the subtle pressure variations generated by infrasound. Globally, networks of microbarometers are maintained by meteorological and seismological organisations. The sensor used for hertz is from a US-based company, Infiltec, which manufactures a small, portable, low-cost infrasound detector, the INFRA20, which can be logged via a serial port to a standard computer. It was initially deployed in the suburbs of Reading, where it measured infrasound from several thunderstorms that had formed over northern France and had moved northwards over the English Channel and into southern England on 18 July 2017. Figure 3 shows a spectrogram - an image that displays the detected infrasonic frequencies - for these events. The spectrogram has a horizontal time axis, and a frequency on the vertical axis, using colour to indicate the amplitude of the signal. Figure 3 shows that, as each thunderstorm approached, infrasound frequencies in the 0.02 to $1 \mathrm{~Hz}$ range were generated. The most intense frequencies were detected from the thunderstorms at 03:00 local time (LT). From 07:00 to 09:00 LT there were different low-amplitude infrasonic waves detected in the 0.5 to $1 \mathrm{~Hz}$ range, likely to be associated with traffic and trains during the morning rush hour. To contextualise this, the infrasonic waves observed here oscillate once over a period of $10 \mathrm{~s}$, whereas the sound from a subwoofer will oscillate over a period of a hundredth of a second.

The INFRA20 was also used to record the infrasonic signal from the aurora borealis at Pallas, northern Finland, in September 2017. The infrasound there had a distinct signature below $1 \mathrm{~Hz}$, as shown in Fig. 4, and was in agreement with Wilson (1969). The scaling of the colour bar in the periodograms shows that the amplitude of the infrasonic signals produced by the aurora is four times smaller than the amplitude of the infrasonic waves of the thunderstorms. Furthermore, the infrasonic signals produced by the aurora occupy a much lower frequency range than the thunderstorms. This shows that different phenomena produce different infrasound signatures. In addition to the recordings made directly with the INFRA20, infrasound data clips were also provided by ARISE2 project members. These included infrasonic recordings of Mount Etna and an F16 jet aircraft accelerating to speeds greater than that of sound. 


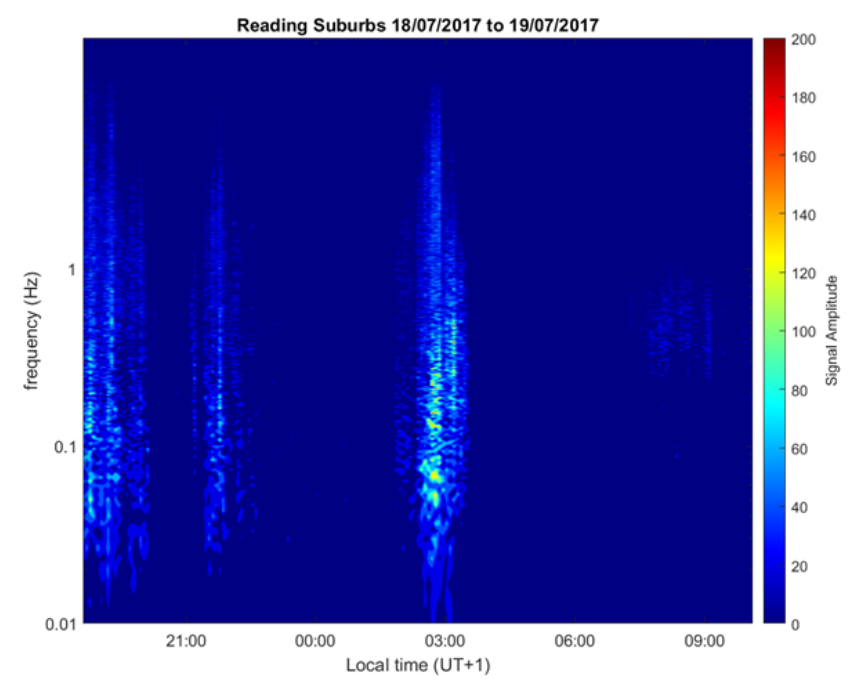

Figure 3. A spectrogram of infrasound data obtained by an INFRA20 sensor situated in the southeastern Reading suburbs from 18 July 2017 to the morning of the 19 July 2017. (On the $x$ axis is the local time in hours; on the $y$ axis is the frequency of the infrasound signals. The colour bar on the right shows the strength of the infrasound signals.).

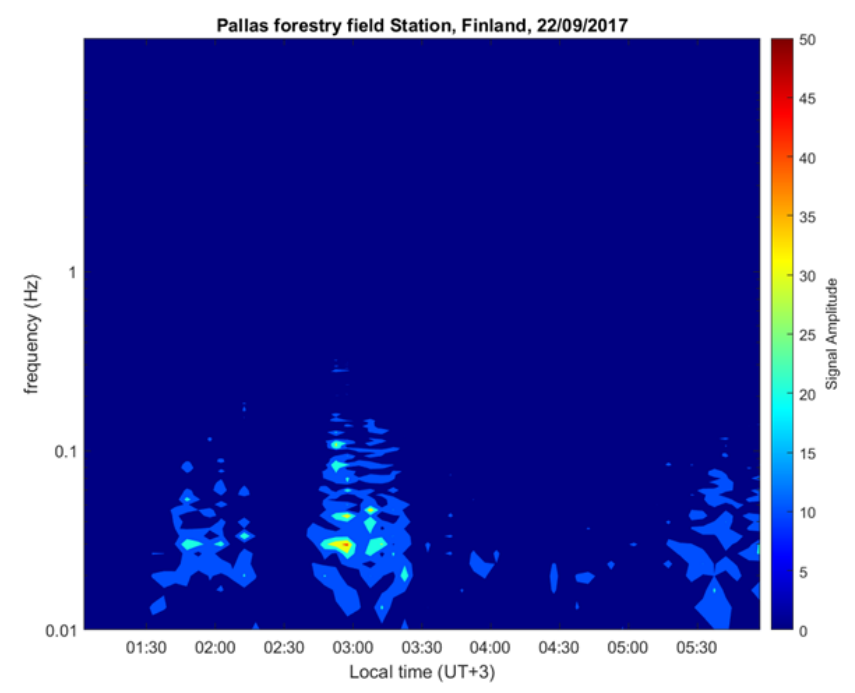

Figure 4. A spectrogram of infrasound data from the INFRA20 sensor placed in Pallas, Finland, on 22 September 2019. (On the $x$ axis is local time in hours; on the $y$ axis is the frequency of the infrasound signals. The colour bar on the right shows the strength of the infrasound signals.).

\subsection{Hertz prototype test rig}

Figure 2 shows a concept picture for the infrasound set-up. For prototyping, a set-up, shown in Fig. 5, using a large subwoofer loudspeaker $(250 \mathrm{~W})$ and an ADX Maximus transducer was implemented. The transducer had a clamp that allowed it to be attached to a chair or wheelchair, which quickly became the furniture of choice for prototyping. Rob-

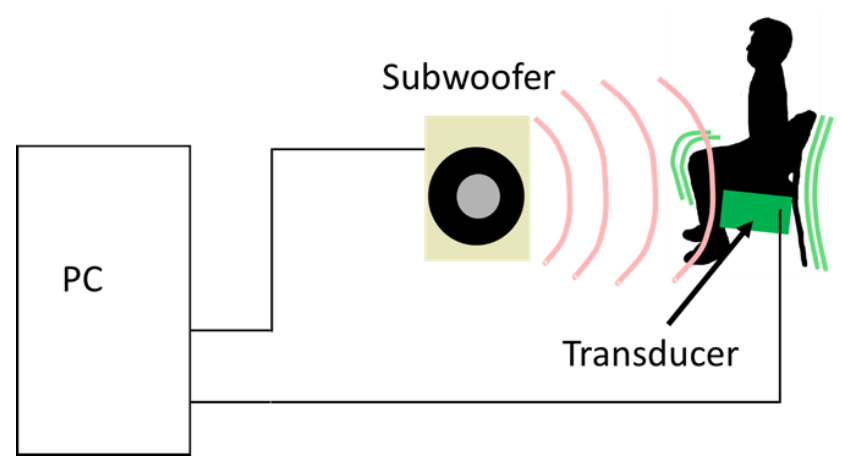

Figure 5. Schematic of the hertz prototype rig.

son had a spare metal wheelchair that was good at transferring vibrations which boasted a variety of possible mounting points where the transducer could be attached. In addition, it was easy to move the wheelchair to different areas of the studio to experience and experiment with different spatial configurations. Both the transducer and subwoofer were connected to the sound card of a computer, meaning that the same processed infrasound signal could be played through both simultaneously. A subwoofer that could play low-frequency sounds down to $60 \mathrm{~Hz}$ was used to increase the immersive experience and so that audiences could be attracted to the installation from a distance. This also stimulated another sense, namely hearing, by providing loud, deep sounds to complement the vibrations provided by the transducer that provided access to the infrasound through physical sensations in the body. The transducer was designed to only play audio signals between 120 and $40 \mathrm{~Hz}$. Given the power delivered through the subwoofer and transducer, the opening track of Pink Floyd's "Dark Side of the Moon" (1973), played merely as a test track, led to tremendous shaking of the modified chair and the studio in which it was placed.

\subsection{Infrasound processing method}

The next part of the project was to turn the infrasonic recordings described in Sect. 2.1 into something that could be played through the transducer and large subwoofer. In their current state, they would be inaudible and would not register on the transducer or subwoofer. In addition to this, background noise, for example from wind passing over the sensor, also needed to be filtered out. To achieve this, a digital bandpass filter was applied over the raw infrasound data. A bandpass filter is a physical or software device which allows a signal with frequencies between two given frequencies to pass, whilst frequencies outside of this range are removed. The spectrograms in Figs. 2 and 3 were used to define the upper and lower limits of the band pass filter by establishing the frequency range in which the infrasonic signatures were largest. 
The first approach was to use the amplitude of the bandpass-filtered infrasound signal to modulate a tone at a range of low frequencies between 60 and $100 \mathrm{~Hz}$. To achieve this, the infrasonic time series was first bandpass filtered to yield BP $(t)$ and was then multiplied, element-wise, by a sine wave of given frequency $f$ to give a sound wave as follows:

$X(t)=\mathrm{BP}(t) \sin (2 \pi f t)$,

where $t$ is the time index. This gave mixed results. At first, it gave an unworldly noise, with the rig making a zooming noise as the shaking and rumbling changed intensity at random speeds, sounding like a science fiction effect. A single tone was successful in yielding an interpretation of infrasound. However, we felt that it did not encapsulate what infrasound might sound like if we could hear it. One thing which was lacking was depth, which was largely due to the monochromatic tone used, and it was felt that a mix of frequencies would amount to a larger sense of resonant layers and a feeling of being immersed in the infrasound. Hence, an alternative was to create a deep cacophony of tones. The method for achieving this was by, firstly, creating pink noise. Noise is sometimes described by likening its spectrum to the optical spectrum of colours. White noise is the hiss noticeable on radios tuned away from a radio station, and its spectral power is constant over all frequency bands. Pink noise's spectral power is inversely proportional to the audio frequency. This gives an effect where low-frequency noise is more dominant than higher frequency noise, giving a rumbling sensation that surrounds and is felt in the body, like sitting on an aeroplane.

The bandpass-filtered infrasound signal was then used to modulate the amplitude of synthetically generated pink noise. To ensure that a deep rumbling was experienced through the prototype rig, a further low-pass filter, a filter similar to the bandpass filter but only removing highfrequency sounds, was then applied. This produced a low rumbling noise to be played through both the subwoofer and transducer, with the rumbling changing in amplitude as determined by the raw infrasonic signal. This produced an effect that we felt was relatable to infrasound, were we able to hear it, while keeping a translatable authenticity, which is something that was important to hertz's ethos. These pink noise-based processed infrasound recordings now had more depth and independent character, depending on the infrasound clip used, which began conveying an emotion and sense of majesty about our planet that the project had yearned to create.

As part of the development process, some of the initial testing was videoed using a smartphone. However, as discussed earlier, low frequencies cannot be detected through conventional sound recording equipment. Thus, on playback through mobile phone or computer, the modulated infrasound was inaudible and only the vocal reactions and the rattling of loose objects on tables were audible. A video ex-

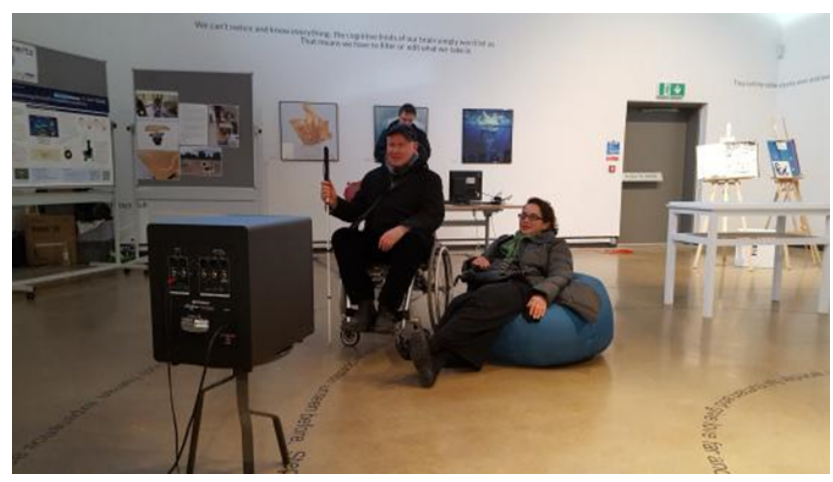

Figure 6. Two people experience the effect of infrasound played through the transducer and large subwoofer in a gallery space. They both face a subwoofer that fills the room with a low-frequency reverberation of sound.

ample from the development phase can be found online at https://doi.org/10.17864/1947.267).

This meant one had to physically be present in order to sense the vibrations. Therefore, in making hertz immersive and experiential, the changes in air pressure caused by the subwoofer can be felt in the space and in the body. The visceral and audible nature of the experience cannot be documented and played back. The infrasound generated is unique to the place in which it was recorded, and that moment cannot be replicated. This is one of the aspects that differentiates hertz from other artworks that use infrasound.

For the interested reader, audio clips where the low-pass filter was set to $300 \mathrm{~Hz}$ can be found at https://doi.org/10.17864/1947.267) which were used on BBC Radio 3's "Late Junction" show with Max Reinhardt. In addition to this, a Supplement has been created that includes, in some further detail, the filter coefficients and the equipment used.

\subsection{Outreach activities and reception}

Initial development of the prototype rig finished in late 2017. Following this, several opportunities arose to demonstrate the prototype rig to the public and experts in both art and science fields. Table 1 shows a list of public outreach events. The largest of these events was the "Be There At The Start" conference hosted at the Attenborough Centre, a contemporary art centre and gallery located in Leicester, United Kingdom. The conference was organised by the project's funders, Unlimited, who facilitate exhibitions of new work by disabled artists in order to reach national and international audiences. Attendees had a wide range of disabilities, and Figs. 6 and 7 show people with visual and hearing impairments, respectively, interacting with the prototype. Accessibility considerations for hertz are considered in Sect. 4.

One of the key questions was to find out what people thought of the artwork and if the experience was uncomfort- 
Table 1. List of public engagement activities where the hertz prototype were shown.

\begin{tabular}{llrl}
\hline Date & Location & People & Audience \\
\hline Nov 2017 & Wyfold Lane studio, Oxfordshire, UK & 11 & $\begin{array}{l}\text { Funders of research and development; potential hertz } \\
\text { supporters and programmers and scientists. }\end{array}$ \\
\hline Mar 2018 & Wyfold Lane studio, Oxfordshire, UK & 25 & Local families and school children \\
\hline Mar 2018 & 101 Outdoor Arts Creation Space, Newbury, Berkshire, UK & 15 & $\begin{array}{l}\text { Resident artists, art commissioners and BBC } \\
\text { Radio 3 presenter, Max Reinhardt }\end{array}$ \\
\hline Mar 2018 & $\begin{array}{l}\text { "Be There At The Start" conference, Attenborough Arts Centre, } \\
\text { Leicester, UK }\end{array}$ & 100 & General public \\
\hline Apr 2018 & $\begin{array}{l}\text { Session EOS8 - scientists, artists and the Earth: co-operating } \\
\text { for a better planet sustainability, EGU 2018, Vienna, Austria }\end{array}$ & 35 & Scientists \\
\hline Apr 2018 & We The Curious, after-hours event, Bristol UK & $50-70$ & Artists \\
\hline
\end{tabular}

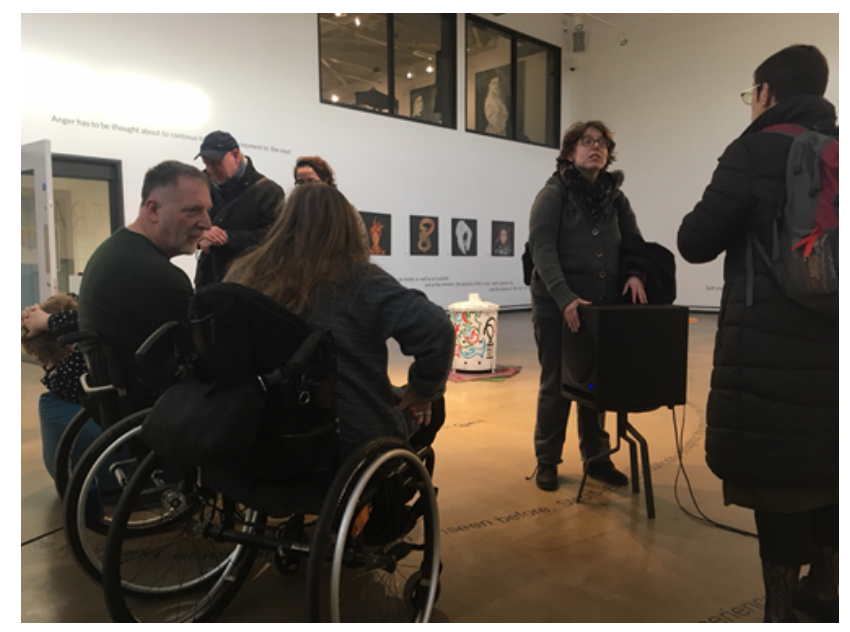

Figure 7. A participant places her hands on the subwoofer to experience the processed infrasound at the "Be There At The Start" festival, Attenborough Centre, Leicester. Photo credit: Glenn Bryant.

able and not enjoyable. Responses were sought from those experiencing the artwork, which included the following:

- "Epic."

- "Ground-breaking."

- "A whole world around me [that] I could not see but felt connected to."

- "In this piece, I can time travel and contemplate the geometry of sound into matter - wow. Mind-blowing and poetic."

- "Incredible vibrations."

- "Primeval, dramatic, disconcerting, and yet thrilling."

While feedback gained was through verbal communication and written comments, the majority reflected enjoyment or an interesting experience. There were no negative comments in terms of discomfort in the written feedback comments, so it is difficult to know whether anybody found the experience uncomfortable. The words "intense" and "soothing" were used in conversations by the visitors. It is possible that, if someone found the experience unpleasant, they left the room and did not comment. But that was not ascertained. Robson experiences chronic pain and had found no ill effects; some vibrations were soothing and some intense, which did not exacerbate her chronic pain. It should be noted that participation was voluntary, and any participant could leave when they wanted to.

In addition to the feedback received in person, Max Reinhardt of BBC Radio 3's "Late Junction" played excerpts of infrasound from the aurora borealis. The infrasound had been reprocessed, so it was just audible for his radio show, and he said, "What a totally astounding and amazing project." There was further positive media coverage of the initial prototyping in Disability Arts Online Magazine (Caulfield, 2017): "Hertz promises to redefine the boundaries of our perception of the stars and the nature of sound." The article later states that "... the hertz team is practically a work of art itself." Kalaugher (2018), who visited hertz at the European Geophysical Union conference in Vienna, Austria, wrote, "It is not every day [that] you get shaken by Etna."

\section{Developing hertz for tour}

Following the running of the prototypes at the venues, shown in Table 1, and the positive feedback from the public, a tour was commissioned which would see hertz being exhibited to the public at three places across the UK. It was realised that, if the installations were to tour, further development would be needed. The first extensive upgrade was to increase the amount of furniture that vibrated, allowing more people to experience the infrasound vibrations. The second was to upgrade the software that played the infrasound through the subwoofer and transducers. This was (a) to make it standalone, meaning minimal operator input, and (b) to configure 
the software to play the infrasound recorded at the locale of the installation in real time. The first part of the work was to replace the wheelchair and attached transducer with more rigid furniture. A steel garden bench and a chair which conducted vibrations well were each fitted with a transducer and linked to the existing subwoofer and playback system. The second part, overhauling the playback system, involved replacing the laptop PC, shown in Fig. 5, with a small, standalone computer (a Raspberry Pi) so it could be easily concealed. The INFRA20 infrasound sensor's cable was extended so it could be placed outside whilst being connected to the Raspberry Pi. Further to this, the Raspberry Pi was configured to obtain data from the infrasound sensor, process it, and play back the processed infrasound signal in real time through the subwoofer and transducers. This allowed the real-time infrasound of a location to be experienced. As computer peripherals such as a mouse, keyboard and monitor would detach from the aesthetics of the installation, the Raspberry Pi was configured to run in a "dead head" mode, meaning that a graphics user interface was not needed and any settings could be altered solely through keyboard commands. The Raspberry Pi was also configured to begin the real-time acquisition of data on start-up, further minimising operator input.

\section{Accessibility considerations}

It was important to all involved in the project that accessibility was incorporated, where possible, from the start, particularly regarding physical access and the interpretation of hertz. From the outset, accessibility considerations, such as wheelchair access to buildings at the University of Reading, allowed Robson to have initial discussions with Marlton. Research, development, and construction inevitably needed to be done in accessible venues and was done at Robson's studio, the University of Reading, and at the 101 Outdoor Arts Creation Space, Newbury, where the finalised version of hertz was constructed.

The furniture used to transmit the infrasound vibrations of the location in real time for the tour were chosen, not only for their conductive qualities and ability to be used outside, but for their sturdiness. The highest seat possible, of this type of furniture, was sourced, allowing it to be sat on easily. In addition to the two benches, a chair with arms was used for visitors who needed more support. During the development phase, the transducers could be transferred to another participant's wheelchair to allow them to partake in the experience without the need to leave their chair. The volume of the sound emitted from the subwoofer was set relatively high for impact and so that visitors could feel it in the air pressure changes and in their bodies. Care was taken not to exceed each venue's health and safety guidelines. The subwoofer was placed in each venue where it was easy to touch and get close to, so that visitors could feel the vibrations and feel the gusts of air pumped out by the speaker as it amplified the sound. Figure 7 shows a deaf visitor touching the subwoofer to experience the processed infrasound.

Physically, all venues used during the tour and described in Sect. 5 had the minimum of wheelchair access, with accessible toilets and lifts. We The Curious, where hertz was installed for three months, had comprehensive access, with detailed information on their website including a virtual accessibility tour called "GoVirtually" that is designed to help people with physical and cognitive disabilities. Guidance from Giraud (2015) was used when creating on-site and online information material for hertz, such as using 14 point sized fonts. For events where the artist or collaborators held discussion sessions, a British Sign Language interpreter could be requested, and subtitles were added to the video made of hertz at the Oxford Science and Ideas Festival (Oxford IF) described in Sect. 5.

Robson is a keen advocate of physical and interpretative access. Her work, at times, plays with more than one sensory aspect; this is an aesthetic decision and does not stem from a deliberate intent to make the work more physically accessible per se. However, hertz enhances accessibility for audiences in that one can both feel and hear the processed infrasound.

\section{Hertz tour}

The tour of hertz occurred at three tour locations, namely the Oxford Science and Ideas Festival, Tramway, Glasgow, and We The Curious at Bristol between October 2018 and February 2019. This section describes the format and set-up of hertz at each location.

\subsection{Oxford Science and Ideas Festival}

The first tour location was the Oxford Science and Ideas Festival on 15 October 2018. Given that the emphasis of the festival was on science and ideas, it was appropriate here that the set-up for the sessions was more educational than artistic. Thus, the scientific research was given more weight than the aesthetic side of hertz. The festival organisers allocated spaces to the diverse events happening during the festival based on their size and technical needs. As can be seen in the video commissioned and produced by Oxford Contemporary Music (https://www.youtube.com/watch?reload=9\&v= 748CLugS1bw, last access: 9 November 2020), hertz was in a room, as opposed to a gallery space, with the equipment such as Raspberry Pi and infrasound sensors on show so that their functionality could be pointed out for discussion. Hertz was presented over the course of a day, with three bookable sessions throughout the day. During these three bookable sessions, visitors were able to meet the artist and collaborators and interact with the artwork, ask questions, react, and explore the concepts and research behind the work and give feedback. The audience was largely made up of families and those with an interest in science, as shown in Fig. 8. Each 
(a)

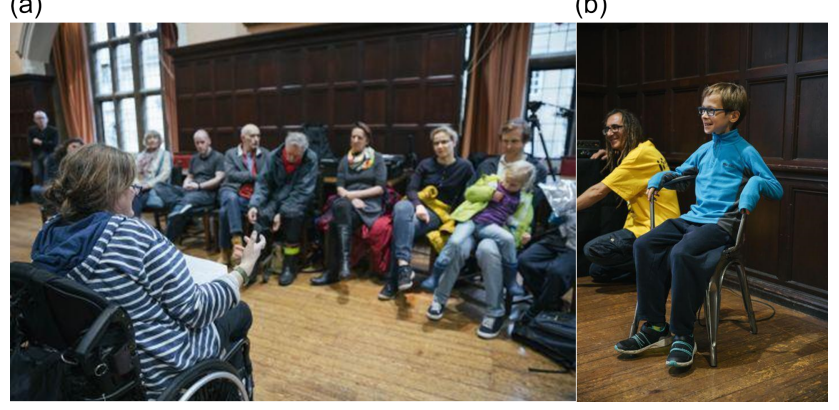

Figure 8. (a) Juliet Robson introduces hertz to the public at the Oxford Science and Ideas Festival, October 2018. (b) A young member of the audience experiences the reverberations of infrasound from the Oxford locality through one of the metal chairs.

session was run so that Robson introduced the project and gave background information before handing over to Chaplin and Marlton, who explained in detail about their respective research and its connection to the two pieces that make up hertz.

\subsection{Tramway, Glasgow}

The second stop of the hertz tour was Tramway, an art gallery space situated in Glasgow, which ran from 18 to 21 October 2018. Here, a more sensorial, experiential encounter that emphasised hertz's aesthetic and conceptual aspects was pursued. Figure 9 shows an image of the infrasound piece from hertz installed in one of Tramway's gallery spaces. Robson had discussions with Tramway's curator and explored the possible gallery spaces available via video call before deciding on where the two pieces that make up hertz would be installed. Since the installation of hertz was complex and was to be undertaken by Tramway's technicians without the presence of the collaborators, a step-by-step instructional video was created. In addition to this, a troubleshooting flowchart to follow in case of technical issues during the exhibition was also sent.

The size of the space chosen for the infrasound piece gave space to each element, namely the subwoofer and each piece of furniture. At one end of the space was a semicircular window overlooking an expanse of Glasgow from which the infrasound recorded in real time was being generated. A bench that had no transducers attached was placed in this window, allowing visitors to overlook Glasgow beneath them while they experienced its inaudible symphony from the subwoofer. The two pieces of furniture with transducers attached were placed further into the space. The Raspberry Pi and infrasound sensor were hidden from view for safety, apart from the leads running across the floor to two pieces of furniture. It was envisaged that the sound from the subwoofer would be heard in the foyer downstairs and would entice people towards the exhibit. On the way into the space, visitors en-

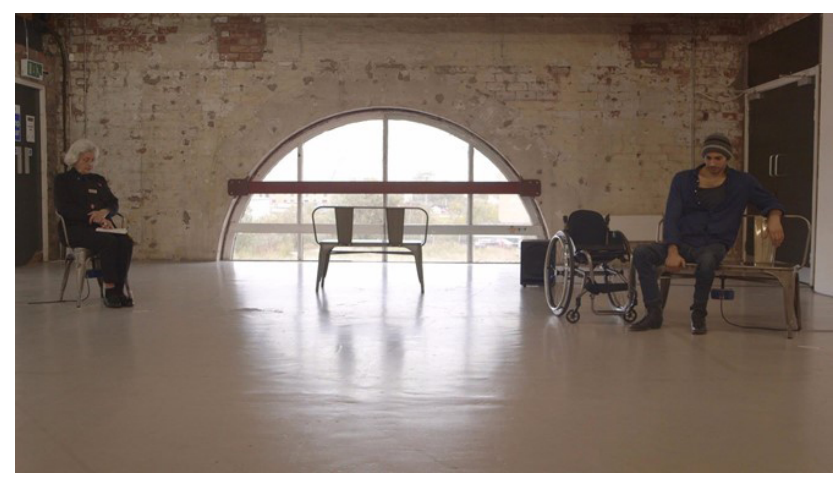

Figure 9. Finalised version of the hertz infrasound installation at Tramway, Glasgow. Two members of the public sit on furniture which have the transducers (blue) clamped underneath. The powerful subwoofer is in the background.

tered through a short corridor past an interpretation board with an overview of hertz. The information on the interpretation board was deliberately minimal and had more conceptual than technical information. This was to see how the work came across as solely a work of art. The idea was that the feedback from visitors would then be applied to the much longer exhibition run at We The Curious in Bristol.

\subsection{We The Curious, Bristol}

The final stop of the tour was at We The Curious, Bristol, between November 2018 and February 2019. We The Curious is a science venue with a dedicated space (called "The Box") for artworks, and hertz was the venue's first commissioned piece. The Box is a small, stand-alone gallery within a science museum, and it was decided that the infrasound piece would work well here. The other part of hertz, featuring the Chladni plates, was installed one floor up, close to the planetarium to catch people interested in space. As a dedicated, recently built gallery space, The Box has several advantages for installing an artwork and deciding on aesthetics. It was possible to lay the cables to the transducers under the floor, and there was also a dedicated lighting rig for the space and the possibility of projection. Figure 10 shows the hertz set-up in The Box at We The Curious.

Like Tramway, the sound of the processed infrasound emitted by the subwoofer could be experienced as visitors entered the building, with the sound drawing them towards the exhibition. As they entered the open doorway of The Box, they saw what looked like three pieces of free-standing metal furniture, each spotlit, with a further spot light above the speaker on a plinth at roughly chest height. A projector displayed text about hertz onto the wall facing the visitors. Otherwise, the space was dark but full of undulating sound that immersed visitors in different qualities that shifted depending on their location within the space. Due to the changing infrasound recorded and replayed in real time in the space, the 


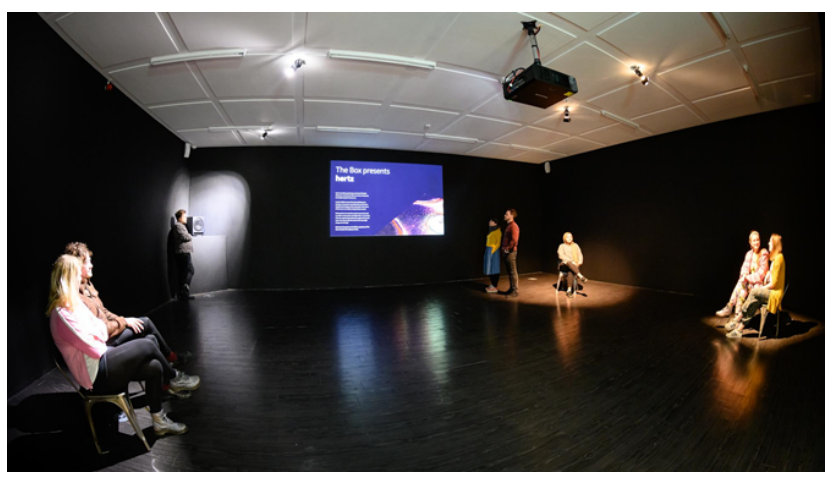

Figure 10. Finalised version of the hertz infrasound installation at The Box at We The Curious, Bristol. Members of the public sit on furniture which has transducers beneath. The subwoofer is located in the far-left corner. Information about hertz is projected onto the wall.

sound that filled the room would vary in intensity and tone constantly, meaning that it was sometimes quiet and gentle and sometimes deep and loud. The visitors had a choice to sit for a while. Depending on the piece of furniture they chose, they would experience strong, light, or no vibrations through their body from contact with the metal of the chair or bench, which was in sync with the louder emissions from the subwoofer. They could also approach the subwoofer and feel the gusts of air being displaced in front of it or feel the vibrations by touching it.

Following feedback from the Tramway at Glasgow (Sect. 6.2), scientific information was included alongside the conceptual interpretation outside of The Box. In addition to the information projected onto the back wall inside, postcards with relevant images, including Fig. 3, and brief facts about infrasound were available. Invigilators were also briefed with information on the project. The roving educational team was briefed on hertz, and the project was included in educational demonstrations of exhibits at We The Curious when they happened.

Table 2 summarises the tour dates and the numbers of visitors. At all three locations a table was present where visitors could leave feedback and take postcards with key facts about the research. To assist in promoting hertz to the public and in increasing the awareness of hertz at the tour locations, hertz was promoted through a Twitter account and website (https://julietrobson.com/blog/, last access: 9 November 2020) launched in mid-2017. The website also included information about the science behind the project. It was also promoted by each venue through their publicity outlets and by the co-commissioners, Oxford Contemporary Music and Unlimited, the core project funder, on their website and social media.

\section{Tour feedback}

As discussed in Sect. 5, there was the opportunity for participating members of the public to leave feedback on flip charts or post cards. Whilst there was much audience participation with the piece, feedback participation varied from venue to venue; like participation, providing feedback was optional. Here we will briefly describe the kinds of feedback received at each venue and then concatenate all the feedback together to see the overall impression the piece had on the audience.

\subsection{Oxford Science and Ideas Festival (IF Oxford)}

The Oxford Science and Ideas Festival (IF Oxford) had prebookable sessions which became fully booked well before the event. This was a good indication that the publicity material was effective. More feedback was received in person rather than from visitors using the feedback materials left out. The video commissioned and described in Sect. 5 documents the day and the reactions of the public. The visitors shown in the video appear to enjoy the hertz installation, with many of the expressions on their face being of people enjoying themselves and being intrigued. During the video, one young visitor left a comment on a whiteboard saying, "I was not into physics, really - until now!" This comment is positive, given that the aims of the project were to build an informative artwork which would also raise the profile of the physical sciences behind the project. One young visitor was so inspired that they got back in touch with the organisers to arrange a work experience week with the co-authors and spend a day at the University of Reading's Department of Meteorology. The feedback left by the public was generally positive, and the keywords from their feedback are studied in the thematic analysis in Sect. 6.4.

\subsection{Tramway, Glasgow}

For the period of the tour at the Tramway, Glasgow, audience footfalls and perceptions were not returned by the venue, meaning that we cannot report back on these aspects. The only information regarding visitor attendance was reported by the gallery staff. who said that a significant number of visitors purposely entered the gallery to see hertz rather than visit the gallery as a whole. The following feedback was reported back from Jo Walmsley, Tramway's curator, and Jo Verrent, senior producer at Unlimited, in response to the installation of hertz:

- Walmsley highlighted a few issues. First, the placement of the main interpretation panel; this was positioned between the works but could be missed by those entering the space from some access routes. In retrospect, she would have had two installed and placed one by each element. The second was an ongoing issue with invigilators who varied in their responses; when visitors wished to discuss the work in more depth, not all answers could 
Table 2. Hertz tour locations and audience numbers.

\begin{tabular}{lll}
\hline Date & Location & Audience numbers \\
\hline 15 Oct 2018 & Oxford Science and Ideas Festival, Oxford, United Kingdom & 55 \\
18-21 Oct 2018 & Tramway art space, Glasgow, United Kingdom & Unknown \\
7 Nov 2018-28 Mar 2021 & We The Curious, Bristol, United Kingdom & 6786 \\
\hline
\end{tabular}

be provided. Third, Walmsey reflected that if they were to restage the work again, they would make a separate, relaxed reading area that could provide more information for those who wished it.

- Verrent commented, "I think it is really interesting how much any artist adds to or distracts from their work, and how much they should or should not be present. It is a huge balancing act, as audiences all want different things. I, personally, missed your wonder and excitement that lies behind the work..., so I think it is interesting to think how this might be brought in..." The idea was brought up by Walmsley and Verrent that a video introduction to hertz was a possible solution to this.

In summary, the feedback from Tramway was that more interpretation information regarding the scientific and technical aspects could have been present and that the experience could have been improved by having the collaborators visit for a question and answer session.

\subsection{We The Curious, Bristol}

The exhibition at We The Curious had, by far, the largest amount of public engagement; this is likely due to the 3 month period that it was installed for. We The Curious staff were able to provide some more in-depth analysis and were able to provide statistics, for example that the average amount of time spent at the infrasound and Chladni plates was 8 and $3 \mathrm{~min}$, respectively, and that the majority of people sat on both pieces of furniture during their visit, broadening their experience. Further to this, $95 \%$ of people who visited engaged with both the infrasound and the Chladni plates. We The Curious were also able to poll people's opinions, and they found that $85 \%$ of visitors said they felt a stronger connection to the hidden sounds of the Earth after visiting the exhibit, and $91 \%$ said they felt they understood more about infrasound based on their interaction with the piece.

\subsection{Overall evaluation of feedback}

In this section, we discuss the content of the feedback from all venues and seek to find out, first, if people felt a stronger connection to the hidden vibrations of the planet and, second, explore the kind of connection this forged with the audience through a thematic analysis to discover underlying themes from the feedback received.

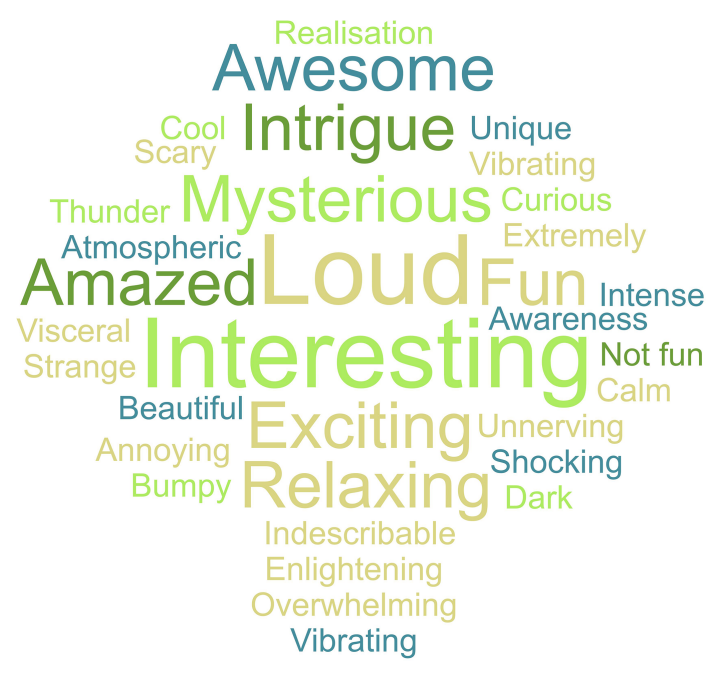

Figure 11. A word cloud summarising the words used to describe the hertz project by the public during its tour.

Data from We The Curious showed that $85 \%$ of the 6786 visitors felt a stronger connection to the hidden sounds of the Earth. This, in short, answers our question about whether audience members felt a stronger connection to the hidden vibrations of the planet. To explore the kinds of connection made, we undertake a thematic analysis. Braun and Clarke (2006) describe a thematic analysis as a method for discovering patterns and themes in qualitative data, for example interviews with people regarding an experience. Here, we perform a thematic analysis on the written feedback received at the venues. First, the written feedback was scanned to search for descriptive words. Figure 11 shows a word cloud showing all the descriptive words gathered from the feedback.

Table 3 shows a thematic analysis of the feedback received. The feedback received was categorised into 11 themes, as shown in column two of Table 3. Audible intensity and tactile themes in the feedback show that participants are relating to one of the main themes of the hertz, namely vibration. The themes of calmness and a sense of grounding indicate that participants felt that hertz created an environment which made them feel more grounded, potentially due to the awareness of their normally inaudible surroundings. The themes of "astonishment", "thrilling", and "captivating" indicate that the project generated interest in the science behind the project in terms of highlighting that infra- 
sound propagates throughout the atmosphere from many different sources, from the aurora to glaciers, and is yet inaudible to humans. The themes of "frightening" and "sense of the unknown" also show that the installation is still making the participants aware of the inaudible world around them and making them aware of the science behind the project. However, the theme "frightening" suggests that they also have a respect for the delicate, yet relentless, natural world around us as they experience hertz. A final theme, "irritable", was found, indicating that perhaps hertz was not for everyone and that the hertz installation caused some participants some discomfort. This could be seen as a barrier to them reconnecting with the hidden vibrations of the Earth.

Due to the logistics of the installation being at We The Curious for three months and the availability for Tramway, it was not possible to have a question and answer session with the co-authors. This leads again to some feedback such as the following:

- "I would love to know more about how you actually interpret that sound. Like, have you just fudged it? Or am I genuinely listening to the sounds of Bristol?"

- "I think it is a really nice approach. It would be nice to have someone actually explain all the science to me... guess you cannot just keep a scientist in a box."

In summary, an exit poll at We The Curious suggests that a vast majority felt more reconnected with Earth's hidden vibrations after visiting hertz. The themes highlighted in the thematic analysis showed that people connected with the vibrations being created and had an increased awareness of the infrasonic sounds generated by the Earth around them. This interest had two schools of thought; one is that of astonishment and awe for our planet. The other was more of fear and shock at the immense power of our planet which produces infrasound. In addition to this feedback, suggested science communication could be improved by having collaborators attend discussion sessions at the venues.

\section{Reviewing the science-art relationship}

In this section we will focus on how the art-science relationship developed over the duration of the project. At the first meeting between Marlton and Robson, Marlton presented a brief introduction on infrasound with much explanation of the terminology through diagrams. Robson, in turn, explained her background in contemporary art and her interest in sound and the invisible and inaudible frequencies of the Earth and cosmos. The discussion then turned to what each party wished to obtain from a potential collaboration. For Marlton, it was to create an outreach activity which used infrasound, highlighting its use in weather prediction, and to highlight the archives of infrasound that are recorded constantly across the globe. For Robson, it was the potential to further explore her research interests in the natural sciences, inspired by her father, Michael Robson, who was a plant physiologist, to develop ways that could be used to make inaudible sound tangible using the latest scientific research. Robson constantly asked questions and Marlton would answer in full in what sounded like a different language; equally, Robson would talk about concepts in contemporary art and receive blank looks from Marlton. However, a positive attitude by both led to their thinking about simplifying the terminology and different ways of explaining concepts. By the end of the first meeting, a rough concept idea had been conceptualised of a piece that could connect people to the hidden resonances of our planet. The initial discussion stages have similarities with art-science collaborations such as MacMullen (2005), where initially the artist is finding out as much about the scientist's research as possible.

The next stage of the project involved visiting each other's working environments. Robson visited Marlton's research institution, and Marlton visited Robson's studio to construct some of the early prototypes and work on the signal processing. It was here that differences in art and science projects differed. Webster (2005) describes that many art-science collaborations come about through an artist being hosted at a research institution. Here, Robson had independently acquired research and development funding from Unlimited, a commissioning organisation who fund artists who have faced access barriers in their careers. The caveat of the grant was that the funding be used to explore proof of concept ideas that need not produce a final working prototype. It is extremely important that artists are able to have time and space to do this and that they are able to follow lines of inquiry and experiment with ideas and concepts without the fear of failure or the constant pressure to produce a fully fledged artwork which stifles creativity and ambition. Marlton said this was an appealing prospect, especially coming from a background where funding is often dependent on proof of concept and goal-oriented outcomes. Indeed, there were no guarantees that what we conceptualised would even work, and the funders understood this.

It would be easy to assume that the relationship between Marlton and Robson was that Marlton was a provider of technology for a preconceived concept developed by an artist. However, this would deny the journey that Marlton and Robson embarked on and the ideas that developed for the demonstrations during the research and development phase and the tour.

At first inspection, it would seem that the project followed a generalisation, outlined in Webster (2005), in that the scientist would provide a technology and the artist would work on curating the conceptual development and communicating the project to venues and the public. For hertz, there are some similarities. Marlton led on the technology development side but was more than a technology provider. For example, he suggested that transducers used for gaming could be used to enhance the physical experience. In addition to this, Marlton spent time testing the effects of different infrasound fil- 
Table 3. Shows a thematic analysis of the feedback from written feedback from the hertz tour.

\begin{tabular}{ll}
\hline Keywords & Theme \\
\hline Loud, extremely loud, intense, overwhelming, thunder & Audible intensity \\
Bumpy vibrating & Vibration \\
Realisation, enlightenment, awareness, visceral & Sense of grounding \\
Relaxing, calm, atmospheric & Calmness \\
Amazement, amazed, awesome, beautiful & Astonishment \\
Fun, excitement, cool & Thrilling \\
Scary, shocking, unnerving, dark & Frightening \\
Unique, indescribable, strange, mysterious & Sense of the unknown \\
Intrigued, interesting, curious, engaging, interactive, fascinating & Captivating \\
Annoying, not fun & Irritable \\
\hline
\end{tabular}

tering parameters and partaking in conversations about how different configurations may alter the authenticity of the final processed output. Thus, he took on a more creative role. Robson, having little to no experience of the technology involved in the sensing of infrasound, learnt from Marlton what he thought was and was not possible with the technological aspects; this in turn informed the development of concepts and what may be possible in the final tour version of hertz.

Working on the project over 2 years enabled Robson and Marlton to hone their methods of communicating complex ideas with each other. Understanding of each other's subject areas developed gradually by being around each other and picking things up; it was an osmosis of knowledge aided with the use of diagrams and developing metaphors for concepts. Towards the end of the project, Robson had a deeper understanding of infrasound, its uses and potential - not only for future artworks but for research - and its current applications. Marlton had a greater understanding and appreciation for contemporary art, particularly interactive art, and its potential to make complex scientific ideas not only understandable but exciting, relevant, and meaningful.

Jeffreys (2018) states, "When it comes to collaboration, there is a danger that generalising about scientists as [being] rational, institutionalised and ends-oriented versus artists [who are] emotional, free, process-driven can risk accentuating disciplinary stereotypes. Or, conversely, that trying too hard to find commonalities can lead to simplistic platitudes about 'creativity'. People are more than the discipline they represent." During this project, such a generalisation as this was avoided, and we felt that the metaphorical wall that exists between the two disciplines was overcome, similar to case studies discussed in Leach (2005).

It became clear that certain methodologies were recognisable to both Robson and Marlton. Both worked with flexible forms of praxis-based research, which could be defined as a form of critical thinking, and comprises the combination of reflection and action taking. This reflection and action taking is demonstrated in Sect. 2.3, when it came to assessing how to best process the infrasound from feedback during the pro- totyping sessions. Ultimately, the project had similarities to that concluded by Stewart (2003) who stated:

The research function of developing and extending knowledge is to be judged on the products of that research. In the same way that a learned paper is evidence and coherent argument for all the processes that preceded it, laboratory or speculative, the finished work of art is the culmination of the theory and practice of the discipline. Based essentially on investigative, exploratory, speculative, or analytical processes, the outcomes are a result of synthesising the problematics of the discipline. Like the best research in any field, it is expected that creative work will comply with the defining characteristics.

It was previously highlighted at the start of the project that Marlton and Robson, whilst being positive, were unfamiliar with each other's subject areas. We reflect here on how these attitudes have changed. In an interview with Liz Hingly for the University of Birmingham's Phyart website, Robson stated:

The project [hertz] is the first time I have worked in depth with scientists. Overall, it has given me an understanding [of] and deeper appreciation for the ways artists and scientists can collaborate, affect each other's work, and learn each other's language. This can only be achieved through a commitment by the artist to meaningfully engage in scientific research and for the scientist to trust in the artist's ability to create something that communicates on both an artistic and scientific level. Finding a successful working partnership, where both parties meet on a common ground, is not easy. Simultaneously, the partial mystery in each other's processes of research and creation motivates the relationship.... My main motivations are to make an outstanding artwork with the use of cutting-edge science that is accessible to as many people as pos- 
sible. Something interactive, intangible, mysterious, an encounter that inspires questions. I do not aspire to be a physicist; I want to retain and share the mystery of true science.

Robson states a deeper appreciation of science-art collaborations due to the work on hertz, and the statement above reflects strongly on the creative development processes discussed here. It also shows how Robson has succeeded in her quest to bring an artwork using cutting-edge science, infrasound, to the public. Marlton was also interviewed by Robson as part of the project about how the project has changed his attitudes:

If I told you I had made a chair that vibrates to the sound of the Earth, people might have been, like, so what? But with the use of Juliet's (Robson) experience, hertz has been presented, raised in profile, and her creative license and skills have been used to create an installation that engages and enthrals the public; I could not have done that myself.

This echoes Marlton's desire, at the beginning of the project, to create an installation that highlights the use of infrasound that the public can engage in. It also highlights the importance of how working with an artist can be used to raise the profile of research, as discussed in Webster (2005). When Marlton was asked about how hertz had changed him as a scientist, he replied:

I am more interested now in different ways of displaying data. I make a data plot and, sometimes, I think we could turn it into something you could feel or hear, and it has opened up new ways of visualising data, especially if it is something quite complex. So, I am more open to when you look at data or something, thinking what could I do with this? I guess, learning from Julie, who looks at something and thinks of several quite out [of] the box things that could be done with it. So, I guess, as a result of hertz, I now think a lot more out of the box.

This is an interesting concept and has been discussed in Eldred (2016) and Segarra (2018), who highlighted how scientists who either view art, create their own art, or work in collaboration with other artists can help boost their problemsolving abilities. This is due to being able to switch focus completely from their own work or view other creative efforts as new perspectives for solving problems.

In summary, hertz did not suffer from the generalisation that the scientist is a technology provider and the artist is the curator of the given technology. Here, that boundary did not exist, and the scientist had a large input into the creative part of the project. Likewise, the artist took an extensive interest in understanding the science involved and was able to input into the design of the technology developed for the project. This was achieved by having a positive attitude and an open mind to learn about completely new subject areas. When collaborating, a similar methodology of action taking and reflection provided a framework for creativity. In addition to this, having a grant that was not issued by a research institution, as is commonly done, allowed the development of hertz to take a more dynamic route, where creativity was prioritised over the need to produce a finalised artwork by a deadline. For Robson, hertz allowed her to gain experience in art-science collaboration that can be applied to future art-science collaborations. For Marlton, his knowledge of contemporary art has increased, along with seeing the benefit of working with artists in the future to boost the visibility of research. It has also opened new avenues in problem solving.

\section{Conclusions}

Here, an art installation named hertz, which was aimed at allowing people to feel reconnected with the environment and was to be used for helping to describe the science of infrasound, was created. This was achieved through a successful research and development phase that allowed ideas to be developed. The subsequent three-stop tour of the UK allowed hertz to be exhibited in an accessible way to the public. Analysis of the feedback received showed that most participants found a deeper connection to Earth and the environment after partaking in hertz. For a future tour of hertz, or a variation thereof, an installation could be set up in an underground station where large sections of the space vibrate and shake. hertz also demonstrates that there is considerable potential for outdoor structures and street furniture to have transducers attached to them, widening opportunities for experiential art. In addition to this, more thought is needed into how to communicate the science behind the installation whilst not detracting from its aesthetic.

The collaboration between the artist and scientist worked well. The key to a successful collaboration was to keep a positive outlook and break the generalisations of scientists being a technology provider and the artist being the curator of the technology. Here, both the artist and scientist broke the metaphorical wall using common methodologies between the two subject areas, which led to a more creative output. The experience of the collaboration has improved each individual's working practice. For the artist, it allows more confidence in forming new art-science collaborations for future works. For the scientist, it allows new perspectives for problem solving. The experience documented here can be used as a model for future art-science collaborations. The authors encourage more science, technology, engineering, art, and maths (STEAM) projects (Seggara et al., 2018) based on their experiences here.

Data availability. Examples of the processed infrasound files and videos from the research and development project are available at https://doi.org/10.17864/1947.267 (Marlton et al., 2020). The feed- 
back from the public cannot be made publicly accessible, firstly, as it has not been digitised and, secondly, as it may contain information that could be used to identify individuals.

Supplement. The supplement related to this article is available online at: https://doi.org/10.5194/gc-3-365-2020-supplement.

Author contributions. GJM and JR prepared the paper and steered both the scientific and artistic development. GJM developed the software and hardware. JR developed the hertz concept, publicised the project, planned the tour and oversaw the logistics.

Competing interests. The authors declare that they have no conflict of interest.

Disclaimer. All feedback received from members of the public has been anonymised where needed. At events where photos and videos were taken, an opt-out policy was adopted where people who did not want to be in the photos or videos were asked to make themselves known or wear a wristband so the photographer knew not to include them in the frame. People experiencing the artwork chose to do so out of their own free will and were free to leave or stop participating in the event at any point.

Special issue statement. This article is part of the special issue "Five years of Earth sciences and art at the EGU (2015-2019)". It is not associated with a conference.

Acknowledgements. Special thanks go to Giles Harrison for his constructive input into helping shape this paper and sharing his experiences of art-science collaborations. Martin West is acknowledged for his support during the 101 outdoor arts residency and for carrying out the on-site installations and strip downs. We thank Kate Stoddart, in her capacity as producer of hertz research and development and expertise in strategic planning for the tour, and independent producer Bill Gee for his advice and support. The hertz tour was part of Season for Change 2018, a UK-wide programme of cultural responses celebrating the environment and inspiring urgent action on climate change in the lead-up to the UN Climate of Parties (COP24) talks in December 2018, which were critical in meeting the targets of the Paris Agreement.

Financial support. This research has been funded by a research and development grant from the arts commissioning body, Unlimited (https://weareunlimited.org.uk, last access: 9 November 2020). It has been co-commissioned and supported by Unlimited, celebrating the work of disabled artists, through funding by the Arts Council England. It was also co-commissioned and supported by We The Curious, Oxford Contemporary Music, and the University of Birmingham. The Friends of the University of Reading provided a small grant to fund the furniture and hardware used dur- ing the project. During the project, Graeme J. Marlton was funded by the ARISE2 project, a collaborative infrastructure design study project funded by the European Commission H2020 programme (grant no. 653980; http://arise-project.eu/, last access: 9 November 2020).

Review statement. This paper was edited by Antonio Menghini and reviewed by Charlie Hooker, Sydney Lancaster, and two anonymous referees.

\section{References}

Aerotope: Infrasound as Art Installation, Aerotope, available at: https://www.aerotrope.com/news-blog/2012/10/12/ infrasound-as-art/ (last access: 31 August 2020), 2012.

Barres, L. C.: Anish Kapoor: "I talked too much. Please, forgive me.", viewed August 31st 2020, available at: https://medium.com/@LauraCalcada/ anish-kapoor-i-talked-too-much-please-forgive-me-f6da379cf425 (last access: 31 August 2020), 2017.

Blanc, E., Ceranna, L., Hauchecorne, A., Charlton-Perez, A., Marchetti, E., Evers, L. G., Kvaerna, T., Lastovicka, J., Eliasson, L., Crosby, N. B., Blanc-Benon, P., Le Pichon, A., Brachet, N., Pilger, C., Keckhut, P., Assink, J. D., Smets, P. S. M., Lee, C. F., Kero, J., Sindelarova, T., Kämpfer, N., Rüfenacht, R., Farges, T., Millet, C., Na“sholm, S. P., Gibbons, S. J., Espy, P. J., Hibbins, R. E., Heinrich, P., Ripepe, M., Khaykin, S., Mze, N., and Chum, J.: Toward an improved representation of middle atmospheric dynamics thanks to the ARISE project, Surv. Geophys., 39, 171-225, https://doi.org/10.1007/s10712-017-9444-0, 2018.

Braun, V. and Clarke, V.: Using thematic analysis in psychology, Qual. Res. Psychol., 3, 77-101, 2006.

Caulified, D.: What if you could hear the stars singing? Juliet Robson's hertz, Disability Arts Online, available at: https://disabilityarts.online/magazine/opinion/ hear-stars-singing-juliet-robsons-hertz/ (last access: 31 August 2020), 2017.

Chaplin, W. J., Kjeldsen, H., Christensen-Dalsgaard, J., Basu, S., Miglio, A., Appourchaux, T., Bedding, T. R., Elsworth, Y., García, R. A., Gilliland, R. L., and Girardi, L.: Ensemble asteroseismology of solar-type stars with the NASA Kepler mission, Science, 332, 213-216, 2011.

Eldred, S. M.: Art-science collaborations: Change of perspective, Nature, 537, 125-126, - How working on a art project changes your perceptions of your own work, 2016.

Ezquerro, L. and Simón, J. L.: "Geomusic as a New Pedagogical and Outreach Resource: Interpreting Geoheritage with All the Senses.", Geoheritage, 11, 1187-1198, 2019.

Ganchrow, R.: On long wave synthesis, in: The Geologic Imagination, Sonic Acts Press Amsterdam, 2015.

Giraud, C: DEMYSTIFYING ACCESS: A guide for producers and performance makers: how to create better access for audiences to performing arts, We are Unlimited, available at: https://www.weareunlimited.org.uk/wp-content/uploads/2015/ 12/Unlimited_ProducersResourcePack-Dec-2015-v2.pdf (last access: 31 August 2020), 2015. 
Gupfinger, R.: Interactive Infrasonic Environment: A new type of sound installation for controlling infrasound, in: WorkshopProceedings der Tagung Mensch \& Computer 2009, Logos Verlag, Linz, Austria, 2009.

Hooker, C.: Audio Accompaniment, Charlie Hooker, available at: https://www.charliehooker.co.uk/cat/8/1 (last access: 31 August 2020), 2011.

Kalaugher L.: EGU 2018: shaken not stirred, Earth Sciences Blog, available at: http://blog.environmentalresearchweb.org/2018/04/ 11/egu-2018-shaken-not-stirred/ (last access: 31 August 2020), 2018

Leach, J.: 'Being in Between': Art-Science Collaborations and a Technological Culture, Soc. Anal., 49, 141-162, 2005.

Marlton, G. and Robson, J.: Supplementary material for "Developing the hertz art-science project to allow inaudible sounds of the Earth and Cosmos to be experienced", University of Reading, Audiovisual, https://doi.org/10.17864/1947.267, 2020.

McMullen, K.: Experimental physics, experimental art, Nature,434, 310-311, https://doi.org/10.1038/434310a, 2005.

Patterson, K.: Vatnajökull (the sound of), available at: http: //katiepaterson.org/portfolio/vatnajokull-the-sound-of/ (last access: 31 August 2020), 2007.

Pink Floyd,: Breeth, Dark Side of the Moon, Harvest Records, 1973. Segarra, V. A., Natalizio, B., Falkenberg, C. V., Pulford, S., and Holmes, R. M.: STEAM: Using the Arts to Train Well-Rounded and Creative Scientists, J. Microbiolo. Biol. Educ., 19, 19.1.53. https://doi.org/10.1128/jmbe.v19i1.1360, 2018.
Stanford, N.: Behind the Scenes, available at: https://nigelstanford. com/Cymatics/Behind_the_Scenes.aspx (last access: 31 August 2020), 2013.

Smets, P., Assink, J., and Evers, L.: The study of sudden stratospheric warmings using infrasound, in: Infrasound Monitoring for Atmospheric Studies, 723-755, Springer, Cham, 2019.

Stewart, R. A.: Practice vs praxis: modelling practitioner-based research, in: Proceedings of the 2002 InSEA World Congress: International Conversations Through Art, Columbia University, Teachers College, Centre for International Art Education Inc. 2003.

Stöckmann, H. J.: Chladni meets Napoleon, The European Physical Journal Special Topics, 145, 15-23, 2007.

Webster, S.: Art and science collaborations in the United Kingdom, Nat. Rev. Immunol., 5, 965-969, https://doi.org/10.1038/nri1730, 2005.

Williams, G.: Are artists the new interpreters of scientific innovation, New York Times, NY, USA, available at: https://nyti.ms/ 2eSmlxt (last access: 31 August 2020), 2017.

Wilson, C. R.: Auroral infrasonic waves, J. Geophys. Res., 74, 1812-1836, 1969. 